\title{
Induction Heating Validation of Dieless Single-Point Incremental Forming of AHSS
}

\author{
Amar Al-Obaidi ${ }^{1, *}$ (D), Verena Kräusel ${ }^{1}$ and Dirk Landgrebe ${ }^{2}$ \\ 1 Institute of Machine Tools and Production Processes IWP, Technische Universität Chemnitz, \\ 09126 Chemnitz, Germany; verena.kraeusel@mb.tu-chemnitz.de \\ 2 Fraunhofer-Institute for Machine Tools and Forming Technology IWU, 09126 Chemnitz, Germany; \\ dirk.landgrebe@iwu.fraunhofer.de \\ * Correspondence: amar-baker-salim.al-obaidi@s2013.tu-chemnitz.de; Tel.: +49-371-531-34693
}

Received: 12 July 2017; Accepted: 21 August 2017; Published: 23 August 2017

\begin{abstract}
Advanced high-strength steel (AHSS) is subject to a high deformation in geometry due to spring-back and high forces during forming. Therefore, dieless single-point incremental forming supported by induction heating was introduced. When a HCT980C steel part was studied, it was observed that the geometrical accuracy increased by forming using a $15 \mathrm{~kW}$ induction power, whereas a high deviation in profile geometry was observed by forming using a $5 \mathrm{~kW}$ induction power. The forming forces decreased by $66.63 \%$ compared with those resulting from forming at room temperature. At the same time, the HCT980C steel part cracked and failed to reach its designed depth when forming at room temperature. Regulating the tensile strength and hardness of the formed part and preventing their reduction was achieved by increasing the feed rate continuously as a function of the formed part's growing depth. Moreover, the distribution of the induction heating temperature was reduced by introducing the new forming strategy. A cone wall angle of $70^{\circ}$ was flexibly formed from a HCT980C steel sheet when the new strategy was applied.
\end{abstract}

Keywords: dieless single-point incremental forming; induction heating; geometrical accuracy; formability

\section{Introduction}

Dieless single-point incremental sheet metal forming (SPIF) by a tool having a single point of contact is a highly adaptable process whereby the part is formed by the movement of a hemispherical tool along a characterized path. SPIF technology is different from other sheet metal forming methods, such as spinning, piercing, deep drawing, and bending. The mechanism of SPIF is plastic deformation caused by directing a forming tool via a path on the sheet metal using a computer numerical control (CNC) machine [1].

Since SPIF is a dieless process, it is suitable to form complicated prototype profiles within a short period at low cost. The most popular parts that were made by SPIF have been used in aerospace or medical applications [2]. Due to the feasibility shown by SPIF, new applications were presented, such as applying heat in forming hard-to-form, high-strength sheet metals.

A new generation in SPIF has started to apply the heat in different ways during forming to form high-strength sheet metals. Laser heating was investigated by [3] where two moving systems were used: one was a robot to move the tool and the other was a 3D coordinator to guide the laser on the sheet. Furthermore, conduction heating was suggested by [4] to heat the sheet metal by electric heaters for forming a 5083 aluminum magnesium alloy.

Another heating method was presented that involved exerting hot oil to increase the sheet metal temperature as described in [5]. In other investigations, an electrical current was applied that passed through the tool to heat up the sheet, which was studied by [6] to form a titanium alloy $\mathrm{TiAl}_{2} \mathrm{Mn}_{1.5}$. 
A hot air medium was tested in [7] as the temperature of AZ31 alloy was increased to $250{ }^{\circ} \mathrm{C}$ and formed it into complicated shapes. Resistance heating was suggested by [8], using two tools held by robots: one to form and the other to support and heat the sheet metal to $600{ }^{\circ} \mathrm{C}$.

It can be concluded from the literature review that there is no heating method accompanied with SPIF that can increase the sheet metal temperature over $750{ }^{\circ} \mathrm{C}$ other than with a laser. However, the laser method was specialized by its complexity.

SPIF has still not been implemented widely in industry for numerous reasons, including:

- Lack of geometrical accuracy in high-strength produced parts [9,10];

- Limited applications, especially for high-strength metals;

- Lack of suitability for difficult-to-manufacture parts with a perpendicular wall angle, such as deep drawing;

- Suitable only for prototype manufacturing because of the time consumed during tool travel along its designed path; and

- Different component properties in comparison to the conventional sheet metal forming technologies.

This paper proposes a method to increase the importance of SPIF by demonstrating induction heating synchronized with SPIF, or induction-assisted SPIF (IASPIF). The availability of a viable induction heating method with SPIF would increase the interest in it. An advantage of our approach is that high-strength sheet metals can be simply formed into complex geometries by adopting a simplified mechanism.

\section{Materials and Methods}

The sheet metal blanks and their specific parameters for our dieless SPIF investigation were tested by many devices to improve the efficacy of the suggested process. It became clear that the process parameters have a very large influence on the experimental results.

HCT980C dual-phase steel is well known as an advanced high-strength steel (AHSS) and was investigated using a sheet with a thickness of $1.2 \mathrm{~mm}$. The steel alloy was supplied by ThyssenKrupp Stahl-Service-Centre (Radebeul, Germany). The full specifications and properties of the mentioned steel alloy can be found in [11].

The experimental setup of the dieless single-point incremental forming process assisted by induction heating was the same as that used in [12] and is illustrated in Figure 1. The forming tool material was made from hot-worked tool steel X210Cr12 (1.2080) with a diameter of $12 \mathrm{~mm}$. The tool is fully quenched and hardened to $64 \mathrm{HRC}$ and forming tips with diameters of 6 and $12 \mathrm{~mm}$ were used. A high frequency induction generator was used with a maximum power capacity of $50 \mathrm{~kW}$ and the magnetic radiation frequency was $325 \mathrm{kHz}$.

An induction coil was connected to the induction generator head which moved simultaneously with the forming tool. A one-turn induction coil utilized in the experiments had outer and inner diameters of 20 and $8 \mathrm{~mm}$, respectively. The coil was made from a rectangular profile with a width of $6 \mathrm{~mm}$ shaping the coil face. It also had a depth of $4 \mathrm{~mm}$, as shown in Figure 2.

The suggested profile geometry was designed by the SOLIDWORKS software and then exported into a step file to obtain the tool path code that is used by the CNC milling machine. The tool path code program was made by a CAM-software named ESPRIT. A Kistler dynamometer (type 9255Asp) made by Kistler Instrumente AG (CH-8408 Winterthur, Switzerland) was utilized to enhance the resulting forming forces.

There were difficulties measuring the generated heat in the assembled system. The thermocouple could not be used because of the continuous movement of both the forming tool on the upper portion and the induction coil in the lower portion of the sheet. Therefore, the induction heating temperature was measured by an infrared (IR) camera (InfraTec type VarioCAM ${ }^{\circledR}$ ) produced by ESW GmbH (Wedel, Germany), which has a measuring range from -40 to $1700{ }^{\circ} \mathrm{C}$. The measuring frequency was 2 
$\mathrm{Hz}$ (2 pictures/sec). The IR camera was adopted to measure the lower portion of the sheet temperature, as in [13].

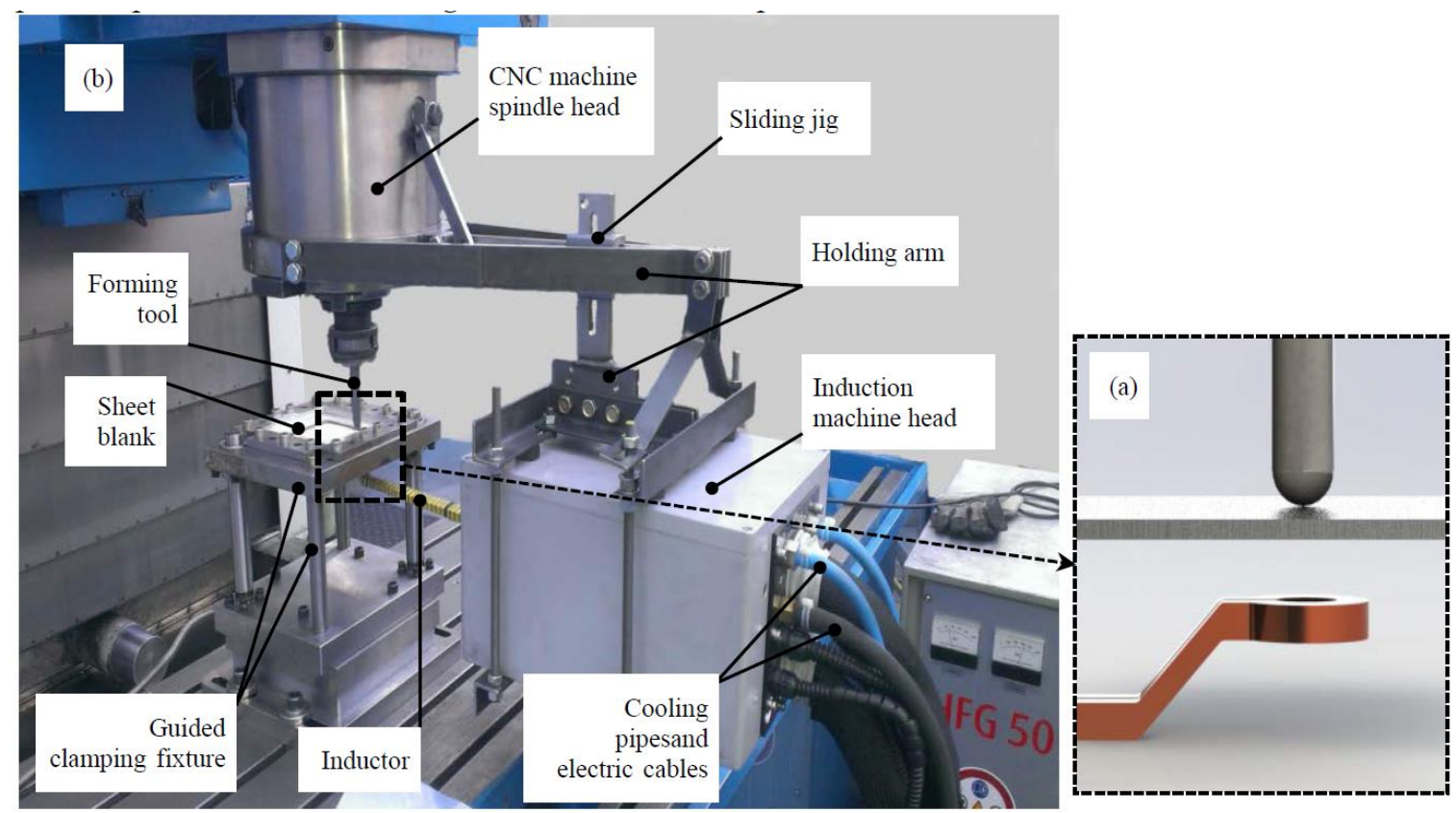

Figure 1. Experimental setup applied in the investigations for IASPIF process. (a) Close up of forming tool and sheet blank; and (b) entire setup.

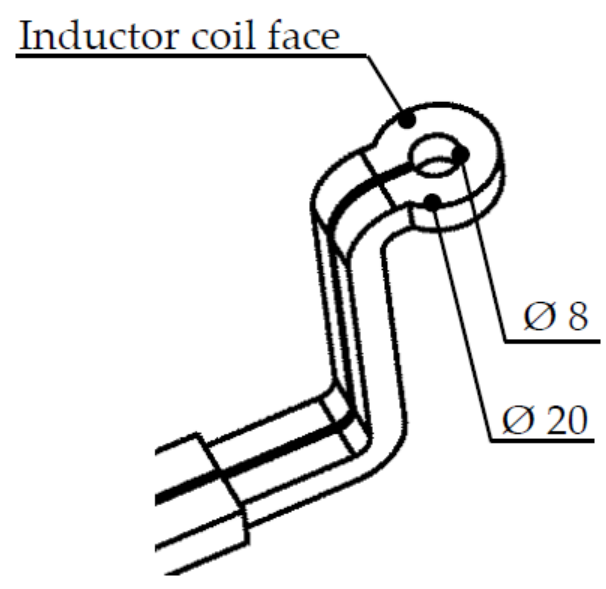

Figure 2. Partial sectional view from induction coil, all dimensions are in $\mathrm{mm}$.

\subsection{Effect of Heat on the Formability of the HCT980C Steel}

As indicated in Figure 3, the increase in temperature caused a reduction in tensile strength and an increase in ductility due to the transformation of the martensitic phase into pearlite and ferrite. These results were obtained by heating up the material to the desired temperature, soaking up to $20 \mathrm{~min}$ and then performing the tensile test. The heating oven was attached to the tensile test machine and the temperature was applied during the tensile test. The tensile tests were carried out according to standard DIN EN 10002-5 by a universal tensile testing machine manufactured by Hegewald and Peschke, GmbH (Nossen, Germany). 


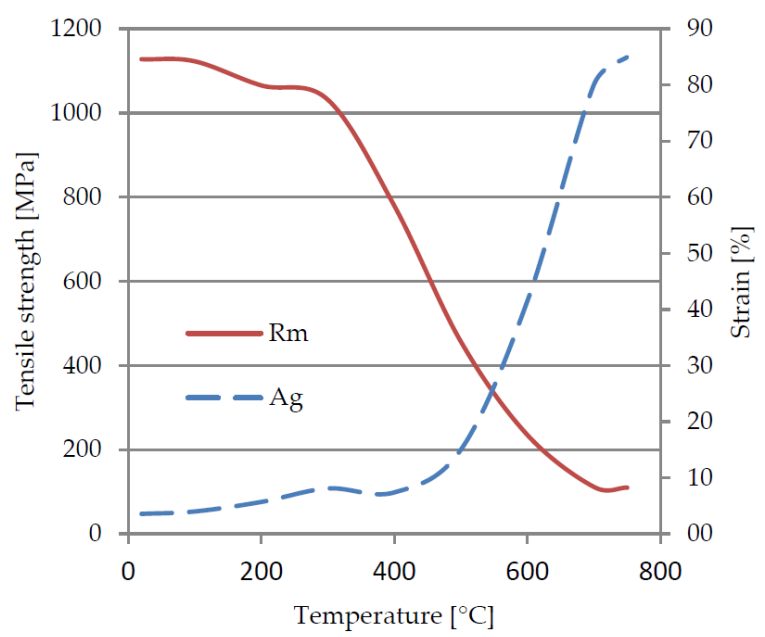

Figure 3. The effect of heating temperature on the mechanical properties of HCT980C steel. $\mathrm{Rm}=$ maximum tensile strength and $\mathrm{Ag}=$ elongation percentage.

\subsection{Experimental Conditions}

The experimental method consisted of producing a conical shape $100 \mathrm{~mm}$ in diameter from the previously stated steel alloy at both room and elevated temperature. The forming parameters used were as follows:

- The incremental step depth in the z-direction for the milling machine was chosen to be $\Delta \mathrm{D}=0.5 \mathrm{~mm}$.

- The starting cone wall angle was $60^{\circ}$ then it was increased until failure. The cone depths were then 50 and $70 \mathrm{~mm}$.

- A graphite powder was sprayed onto the sheet face as a dry lubricating medium because it is not possible to use a liquid lubricant at high temperatures.

- The original dimensions of the tested sheet blank were $190 \mathrm{~mm} \times 190 \mathrm{~mm}$.

- No supporting plate was applied in the experiments due to the movement of induction coil in the lower side of the sheet.

- Tensile test samples were cut by a water jet cutting machine from profiles that were formed from a $150 \times 150 \mathrm{~mm}$ pyramid. Additionally, these samples were utilized to investigate the resulting strength for the HCT980C steel after induction heating.

\subsection{Additional Tests to Improve the Feasability of the Suggested Study on the HCT980C Steel}

The formed profiles were scanned by an Atos Core 200 measuring system manufactured by GOM-Gesellschaft für Optische Messtechnik mbH (Braunschweig, Germany). The microhardness tests were conducted on an M1C automated hardness testing system manufactured by EMCO-TEST Prüfmaschinen GmbH (Kuchl, Austria).

\section{Results and Discussion}

The results contained useful information about HCT980C steel behaviour during dieless hot SPIF. The formability was increased by forming cone wall angles of $62^{\circ}$ for HCT980C steel. A new forming technique was developed by forming with variable feed rates during the operation. Initial investigations were done without applying induction heating, forming at room temperature to compare to the parts that were formed by applying induction heating later at elevated temperatures. 


\subsection{The Effect of Induction Power on the Geometrical Accuracy}

The accuracy of the conical parts that were formed from HCT980C steel was measured by a GOMATOS scanning system as the cone profile was clamped by a fixture to guarantee the exact measuring position, as stated in [14]. The scanned profiles represent the formed parts produced during the experiment. The scanned profiles were merged and compared with those designed by the CAD program SOLIDWORKS. The rapprochement between the scanned and the CAD models was done by applying the GOM inspect program. The actual model was placed over the CAD model for the comparison. Figure 4 shows the CAD model of the cone shapes used in this study. Each point on the CAD model was compared with the respective points in the actual model and the combined deviations of the two models appeared as color-scaled deviations.
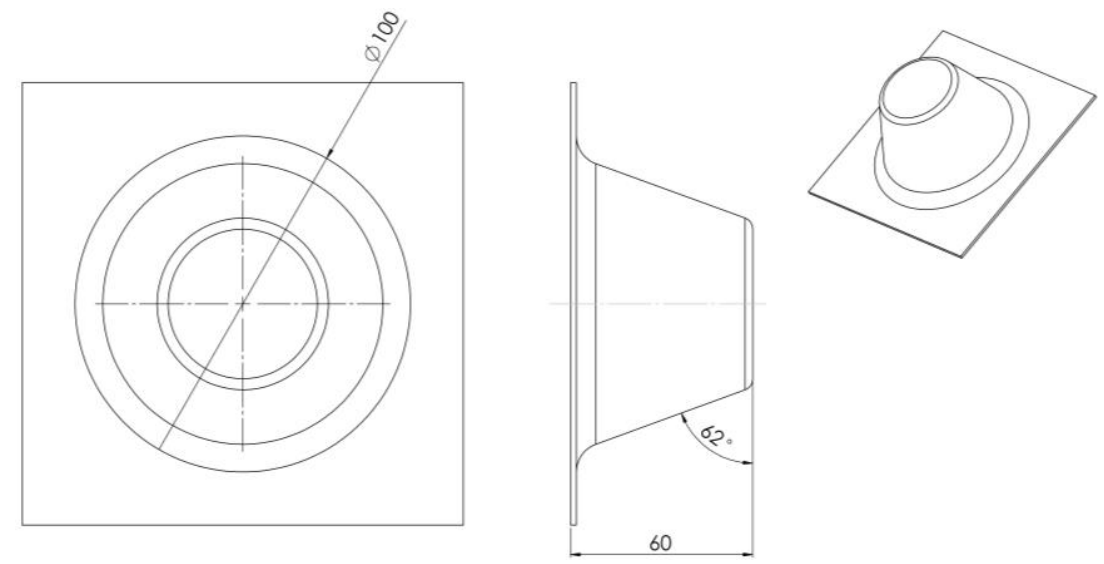

Figure 4. CAD model of cone shapes used in this study.

The most striking results came from the comparison of the scanned profiles and CAD models as indicated in Figure 5. The higher the induction power, the lower the difference between the CAD and scanned profiles. These results correlate satisfactorily with Magnus [15] (p. 118) which stated that a more accurate geometry was formed by a higher laser power that generated higher temperatures.

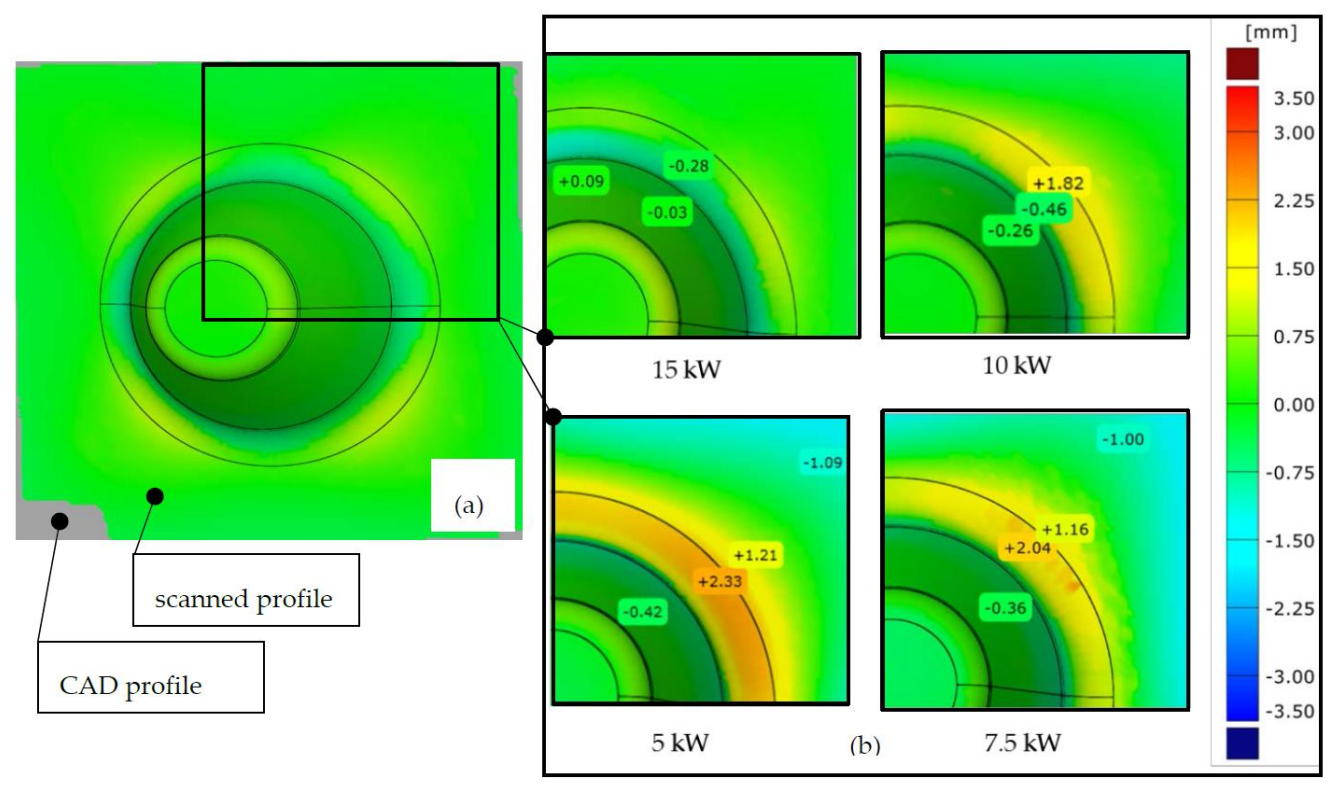

Figure 5. (a) $3 \mathrm{D}$ geometrical scan compared with CAD profiles formed by $62^{\circ}$ cone wall angle; and (b) quartered sections showing comparisons for different induction heating powers. 
The negative deviations presented in Figure 5 mean that the scanned part level is lower than the CAD profile level. However, the positive deviations express that the scanned part level is higher than the CAD profile level.

\subsection{The Effect of Induction Heating on the Forming Forces}

The measured forming forces are shown in Figure 6 for HCT980C steel.

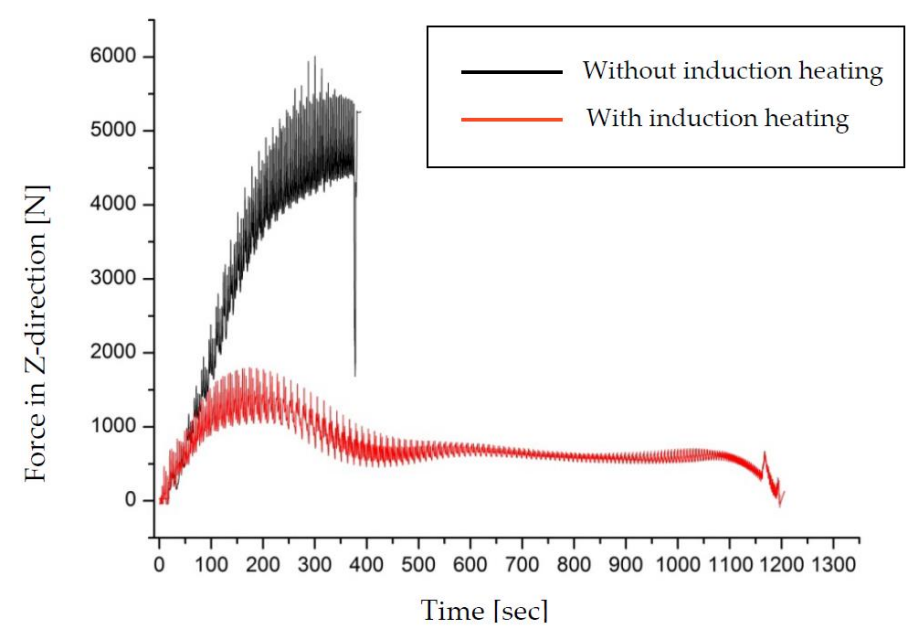

Figure 6. Force in the z-direction during forming both with and without induction heating at a power of $12.5 \mathrm{~kW}$ for $62^{\circ}$ cone wall angle test samples formed at a $1.5 \mathrm{~m} / \mathrm{min}$ feed rate.

The forces in the z-direction without induction heating (room temperature) exceed $5500 \mathrm{~N}$. The forces during induction heating were limited to $1850 \mathrm{~N}$. It is, therefore, not possible to form the HCT980C steel at room temperature.

The high fluctuation in the forming forces was also discovered by [16]. The pulsing phenomenon in the forming forces was caused by continuous movement of the forming tool on the sheet blank. A calibration process was performed to validate the measured forces in the $\mathrm{z}$-axis direction equal to $\pm 5 \mathrm{~N}$.

\subsection{Influence of Induction Heating on the Microhardness and Mechanical Properties}

The maximum tensile strength of HCT980C steel as delivered was $1000 \mathrm{MPa}$, but after forming at a feed rate of $1.5 \mathrm{~m} / \mathrm{min}$ and using an induction power of $12.5 \mathrm{~kW}$, the resulting tensile strength decreased to approximately $540 \mathrm{MPa}$. The obtained tensile strength after forming was extracted from a tensile test sample that was described in Section 2.2.

The HCT980C tensile strength was significantly influenced when heated to more than $750{ }^{\circ} \mathrm{C}$ as investigated by [17]. The sample temperature reached $790{ }^{\circ} \mathrm{C}$ when formed at a feed rate of $1.5 \mathrm{~m} / \mathrm{min}$ and using an induction power of $12.5 \mathrm{~kW}$ as shown in Figure $7 \mathrm{a}$. At the same time, the formed cone was divided into 3 equal zones as shown in Figure $7 \mathrm{~b}$, and the microhardness values of each zone were found different from the neighbouring zone. Furthermore, the total cone height was $70 \mathrm{~mm}$, therefore, each zone was approximately $23.33 \mathrm{~mm}$ in length.

As indicated in Figure 8, the minimum microhardness was observed in the third zone due to the reduction of the cone diameter during forming. It appears that heat dissipated more so in the large cone area and was generated more so in the smaller cone area. Figure 8 indicates that the minimum microhardness values were located in the upper end of the smaller cone area. In addition, in the smaller cone area the microhardness reached 106 HV1. The as-delivered microhardness of HCT980C steel is 340 HV1, which corresponds to the area that is located in the first zone. 
A very large difference in mechanical properties between the as-delivered and the hot-formed metal has been observed. This phenomenon was also reported in [18] (p. 218), where the author stated that the microhardness of the DC01 steel decreased after hot forming.
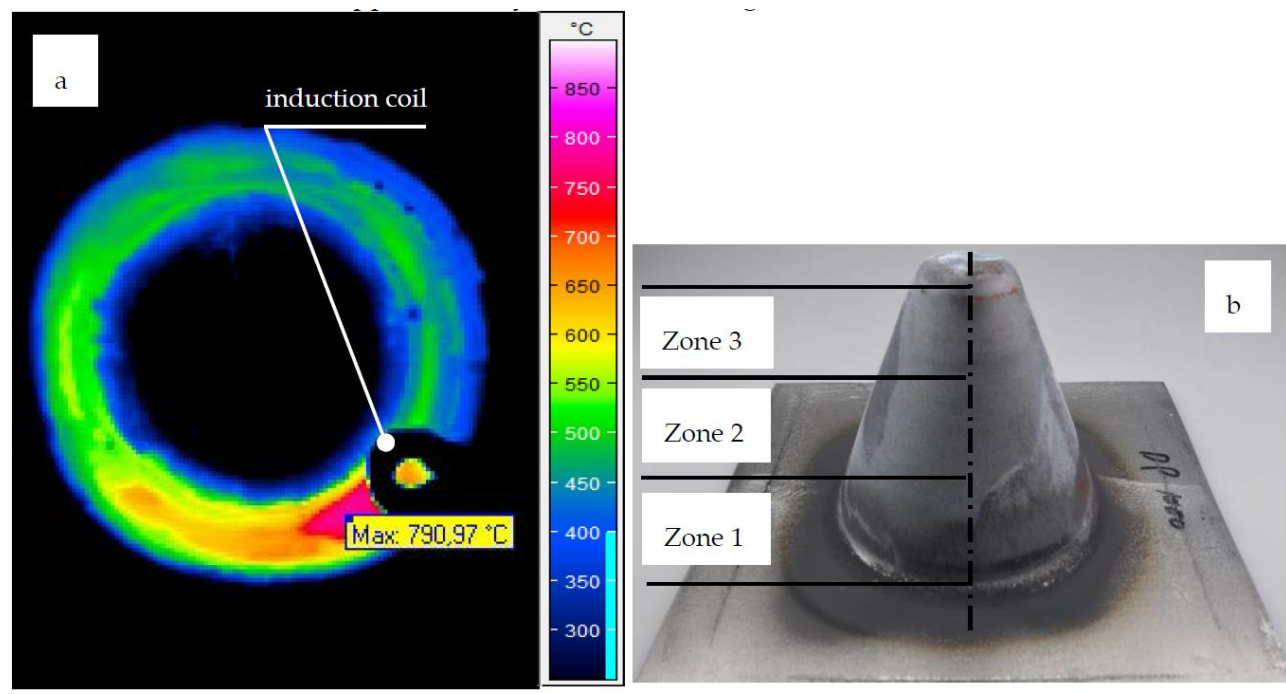

Figure 7. (a) Thermographic image taken by IR camera showing the inductor and the heat generated during induction heating and forming; and the (b) formed cone from HCT980C steel divided into three zones.

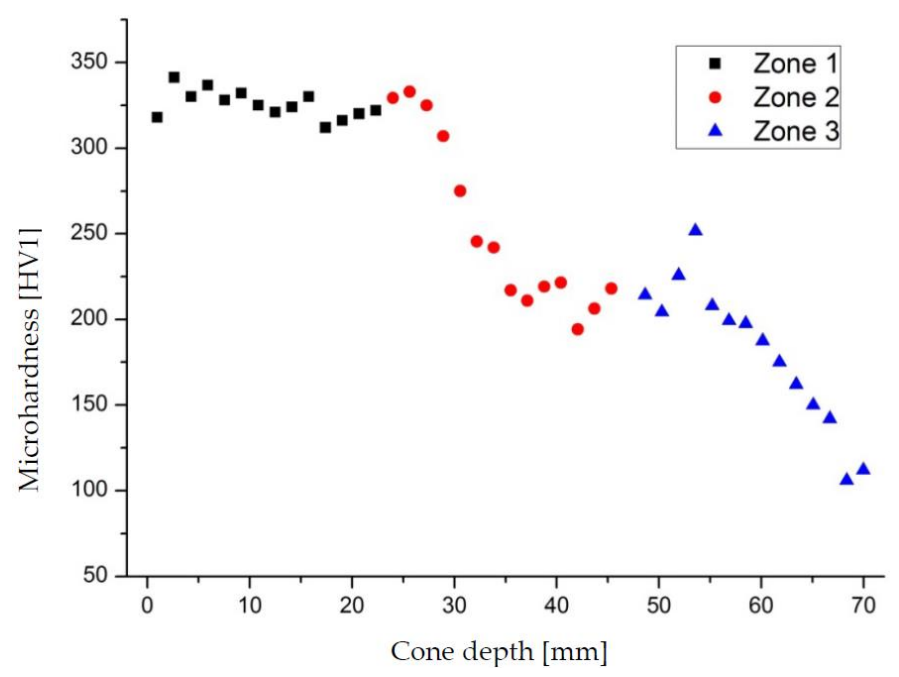

Figure 8. Microhardness vs. cone depth for the three zones in the Figure $7 \mathrm{~b}$.

\subsection{Applying a New Forming Technique}

Most researchers who studied hot incremental forming have suggested a constant feed rate during forming and controlled the increase in heat by methods, such as those in [19], which require large and expensive components.

In this work, the effect of induction heating during forming of HCT980C steel was observed to reduce the tensile strength and microhardness of the formed part. Therefore, it is necessary to find a new technique to improve the tensile strength and microhardness for the produced part. 


\subsubsection{New Forming Technique}

The new forming technique is done by forming at a varied feed rate instead of forming at a constant feed rate. In our experiment, the depth of the formed cone was $50 \mathrm{~mm}$ and it was divided into eight sections. The feed rate changed from 1.5 to $4.125 \mathrm{~m} / \mathrm{min}$ as demonstrated in Table 1 below.

Table 1. The feed rate as a function of cone depth during forming.

\begin{tabular}{ccccccccc}
\hline Forming feed rate $(\mathrm{m} / \mathrm{min})$ & 1.5 & 1.875 & 2.25 & 2.625 & 3 & 3.375 & 3.75 & 4.125 \\
Cone depth in (mm) from-to & $0-10$ & $10-15$ & $15-20$ & $20-25$ & $25-30$ & $30-35$ & $35-40$ & $45-50$ \\
\hline
\end{tabular}

The feed rate was changed in the CNC milling machine code program by writing the suitable feed rate for each depth in the z-direction. A large number of feed rates were investigated during initial experiments. This technique depends on changing the feed rate with cone depth during on-line forming operations, which also serves to control the heat distribution in the formed part shape. The optimum feed rates as stated in Table 1 were selected carefully according to the resulting mechanical properties of the formed part as described in the next section.

\subsubsection{Effect of the New Technique on Heating Temperature}

Using the feed rates in Table 1, the heat distribution over the entire cone profile was shown to be homogenous. The measured temperature for the new technique that uses a variable feed rate is compared to the temperature for the constant feed rate in Figure 9.

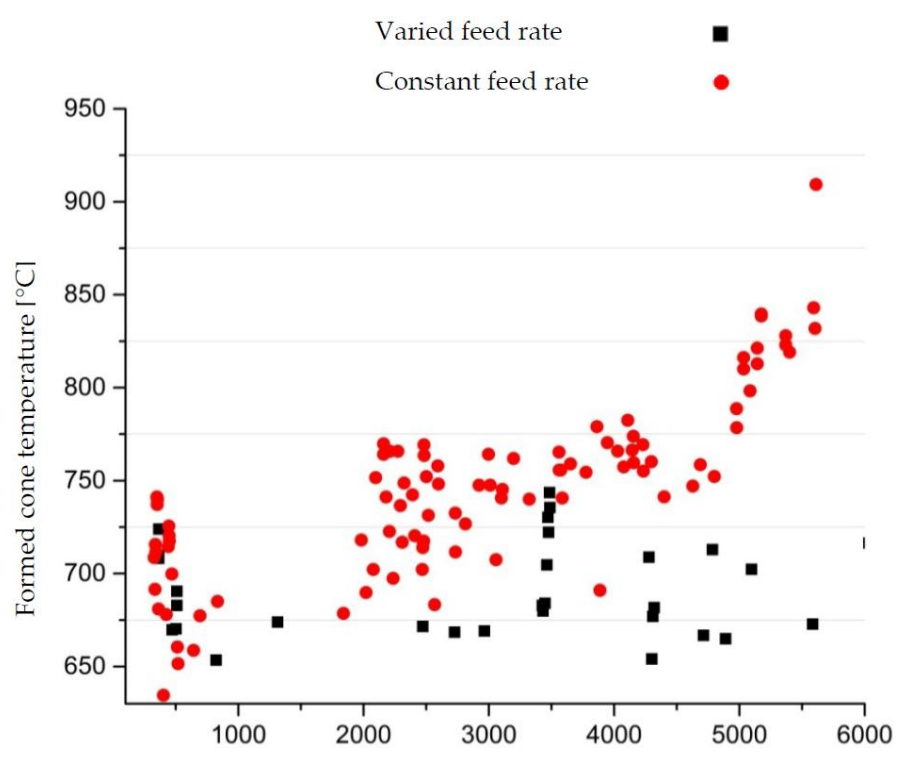

Figure 9. The temperature distribution on a $62^{\circ}$ wall cone during forming with a constant and varied feed rates from the beginning until the end of the operation.

We also observed that when forming with a constant feed rate, the heating temperature increased from $625^{\circ} \mathrm{C}$ to more than $900{ }^{\circ} \mathrm{C}$ from the beginning to the end of the process. When applying the new technique, the temperature was between $650{ }^{\circ} \mathrm{C}$ to $750{ }^{\circ} \mathrm{C}$ during the entire forming operation. The mechanical properties obtained from the tensile samples after $20 \mathrm{~min}$ of soaking as stated in Section 2.1 were not like those obtained from the instantaneous sheet heating by induction synchronized with SPIF. 


\subsubsection{Influence of the New Technique on Formed Part Properties}

The tensile strength of the produced parts when forming with the new technique was between 880 to $690 \mathrm{MPa}$, which is much better than those listed previously in Section 3.3. At the same time, the obtained microhardness was increased in a homogenous distribution between 270 to $330 \mathrm{HV} 1$ for all zones in the cone depth.

\subsection{Improving the Formability}

The findings of this investigation indicate the capability to form cone wall angles of $70^{\circ}$ in HCT980C steel when using a varied feed rate, as shown in Figure 10 . The formed $70^{\circ}$ wall angle was accomplished by using an $8 \mathrm{~mm}$ tool tip diameter.

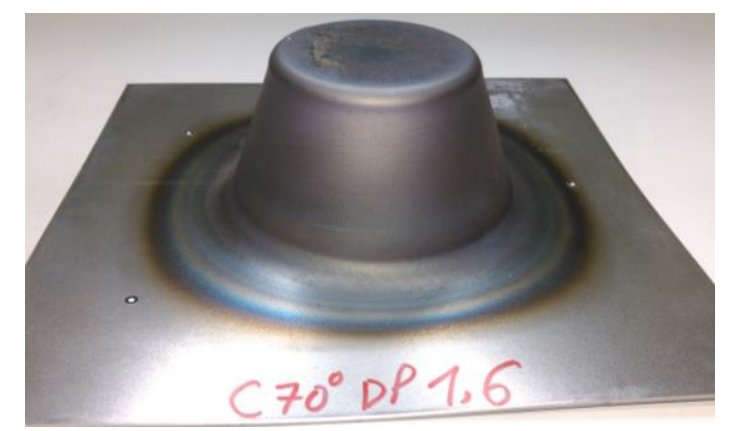

Figure 10. A $70^{\circ}$ cone wall angle by a varied feed rate made form HCT980C steel.

\section{Conclusions and Outlook}

A cone shape in HCT980C steel was accomplished using SPIF assisted by induction heating. The geometrical accuracy was enhanced by varying the feed rate and increasing the induction power.

The forming force generated during induction heating was reduced to $1850 \mathrm{~N}$ from $5500 \mathrm{~N}$ that was generated during forming at room temperature.

This investigation proposed a method to form the AHSS aided by induction heating, but disadvantages due to excessive heating rates were observed. The excessive heating rates caused an increase in ductility and reduction in the hardness of the formed part. However, a smart solution was introduced to solve the ductility and hardness problem by forming at a variable feed rate ranging from 1.5 to $4.125 \mathrm{~m} / \mathrm{s}$. The difference in heating temperature at the beginning and the end of forming time in constant feed rate was $275^{\circ} \mathrm{C}$. However, by applying the new method, the difference from the beginning to the end of the forming time was less than $100^{\circ} \mathrm{C}$. The formability of HCT980C steel was demonstrated by forming a part with a $70^{\circ}$ wall angle.

Future investigations could include heating the sheet up to $900{ }^{\circ} \mathrm{C}$ and performing a quenching operation to increase the hardness during forming. This can be done by using a quenchable steel to make a tailored part of different strength zones.

Acknowledgments: The authors would like to thank the Institute of Machine Tools and Production Processes IWP at the TU Chemnitz and the Fraunhofer Institute for Machine Tools and Forming Technology IWU for their support.

Author Contributions: A. Al-Obaidi conceived and designed the experiments; A. Al-Obaidi performed the experiments; A. Al-Obaidi and V. Kräusel analyzed the data; A. Al-Obaidi contributed reagents/materials/analysis tools; A. Al-Obaidi and V. Kräusel wrote the paper; and all authors participated in the elaboration and discussion of the manuscript.

Conflicts of Interest: The authors declare no conflict of interest. 


\section{References}

1. Jeswiet, J.; Micari, F.; Hirt, G.; Bramley, A.; Duflou, J.; Allwood, J. Asymmetric single point incremental forming of sheet metal. CIRP Ann. Manuf. Technol. 2005, 54, 88-114. [CrossRef]

2. Ambrogio, G.; de Napoli, L.; Filice, L.; Gagliardi, F.; Muzzupappa, M. Application of incremental forming process for high customised medical product manufacturing. J. Mater. Process. Technol. 2005, 162-163, 156-162. [CrossRef]

3. Duflou, J.R.; Callebaut, B.; Verbert, J.; de Baerdemaeker, H. Laser assisted incremental forming: Formability and accuracy improvement. CIRP Ann. Manuf. Technol. 2007, 56, 273-276. [CrossRef]

4. Hino, R.; Nagaishi, N.; Yamamoto, Y.; Naka, T.; Yoshida, F. Incremental forming with local heating for aluminum-magnesium alloy sheet. In Proceedings of the 11th International Conference Technology Plasticity (ICTP 2014), Nagoya Congress Center, Nagoya, Japan, 19-24 October 2014; pp. 946-949. [CrossRef]

5. Galdos, L.; de Argandoña, E.S.; Ulacia, I.; Arruebarrena, G. Warm incremental forming of magnesium alloys using hot fluid as heating media. Key Eng. Mater. 2012, 504-506, 815-820. [CrossRef]

6. Fan, G.; Gao, L.; Hussain, G.; Wu, Z. Electric hot incremental forming: A novel technique. Int. J. Mach. Tools Manuf. 2008, 48, 1688-1692. [CrossRef]

7. Weise, D.; Landgrebe, D. Development of a new variant of incremental sheet metal forming using heated air. In Proceedings of the IDDRG 2015 Conference, Shanghai, China, 31 May-3 June 2015; pp. 90-97.

8. Meier, H.; Magnus, C.; Buff, B.; Zhu, J.H. Tool concepts and materials for incremental sheet metal forming with direct resistance heating. Key Eng. Mater. 2013, 549, 61-67. [CrossRef]

9. Meier, H.; Magnus, C. Incremental sheet metal forming with direct resistance heating using two moving tools. Key Eng. Mater. 2013, 554-557, 1362-1367. [CrossRef]

10. Mohammadi, A.; Vanhove, H.; Van Bael, A.; Duflou, J.R. Towards accuracy improvement in single point incremental forming of shallow parts formed under laser assisted conditions. In Proceedings of the 16th International Conference on Sheet Metal, SheMet 2015, Erlangen, Germany, 16-18 March 2015; pp. $173-178$. [CrossRef]

11. Neugebauer, R.; Göschel, A.; Rautenstrauch, A.; Meza-García, E. Influence of the steel alloy composition on phase transitions and its applicability to hot forming process. In Proceedings of the 10th International Conference Technology Plasticity (ICTP 2011), Aachen, Germany, 25-30 September 2011; pp. 429-434.

12. Al-Obaidi, A.; Kräusel, V.; Landgrebe, D. Hot single-point incremental forming assisted by induction heating. Int. J. Adv. Manuf. Technol. 2015, 82, 1163-1171. [CrossRef]

13. Fan, G.; Gao, L. Mechanical property of Ti-6Al-4V sheet in one-sided electric hot incremental forming. Int. J. Adv. Manuf. Technol. 2014, 72, 989-994. [CrossRef]

14. Duflou, J.R.; Callebaut, B.; Verbert, J.; De Baerdemaeker, H. Improved SPIF performance through dynamic local heating. Int. J. Mach. Tools Manuf. 2008, 48, 543-549. [CrossRef]

15. Magnus, C.S. Lokale Joulesche Erwärmung der Umformzone in der Roboterbasierten Inkrementellen Blechumformung; Shaker Verlag GmbH: Herzogenrath, Germany, 2015; ISBN 978-3-8440-3618-3.

16. Aerens, R.; Eyckens, P.; Bael, A.; Duflou, J.R. Force prediction for single point incremental forming deduced from experimental and FEM observations. Int. J. Adv. Manuf. Technol. 2009, 46, 969-982. [CrossRef]

17. Zhao, Z.; Jin, G.; Niu, F.; Tang, D.; Zhao, A. Microstructure evolution and mechanical properties of $1000 \mathrm{MPa}$ cold rolled dual-phase steel. Trans. Nonferr. Met. Soc. China 2009, 19, s563-s568. [CrossRef]

18. Callebaut, B. Sheet Metal Forming By Laser Forming and Laser Assisted Incremetal Forming; Katholieke Universiteit Leuven: Leuven, The Netherlands, 2009.

19. Göttmann, A.; Bailly, D.; Bergweiler, G.; Bambach, M.; Stollenwerk, J.; Hirt, G.; Loosen, P. A novel approach for temperature control in ISF supported by laser and resistance heating. Int. J. Adv. Manuf. Technol. 2012, 67, $2195-2205$. [CrossRef]

(C) 2017 by the authors. Licensee MDPI, Basel, Switzerland. This article is an open access article distributed under the terms and conditions of the Creative Commons Attribution (CC BY) license (http://creativecommons.org/licenses/by/4.0/). 